\title{
Reflexiones sobre los cambios en las relaciones de género en las familias y paternidad en México*
}

\author{
Cómo citar este artículo: \\ Salguero-Velázquez, M. A. (2021). \\ Reflexiones sobre los cambios en las \\ relaciones de género en las familias \\ y paternidad en México. Revista \\ Latinoamericana de Estudios de Familia, \\ 13(2), 101-119. https://doi.org/10.17151/ \\ rlef.2021.13.2.6
}

María Alejandra Salguero-Velázquez ${ }^{* *}$

Recibido: 12 de octubre de 2020

Aprobado: 27 de abril de 2021

\begin{abstract}
Resumen: Objetivo. El objetivo del presente trabajo es reflexionar sobre los cambios en las relaciones de género en las familias y paternidades en México. Metodología. Metodológicamente se consultó información documental entre 1987 a 2020. Se incorporan textos clásicos que permitan situar los cambios en los significados en torno a la infancia y la relación de los padres con los hijos, ya que no siempre se consideró prioritaria la relación, cuidado y atención como lo es hoy día. Resultados. Los resultados muestran cómo las transformaciones culturales a partir de los compromisos en las conferencias internacionales de Población y Desarrollo, y mundiales sobre la mujer, Ciudad de México (1975) y Beijing (1995), incorporan acciones para involucrar a los hombres en la igualdad de género y la paternidad. Conclusión. La conclusión plantea cómo la involucración en las familias les lleva a conciliar la participación en diversos ámbitos, construyendo identidades complejas como hombres/ parejas/padres/trabajadores.
\end{abstract}

Palabras clave: género, familia, paternidad, identidad.

\footnotetext{
*El artículo se deriva de la investigación "El significado y la doble mirada de la paternidad con hijas e hijos adultos". PAPIIT IN307821, DGAPA, UNAM.

** Universidad Nacional Autónoma de México. Ciudad de México, México. E-mail: alevs@unam.mx.

(iD orcid.org/0000-0002-8610-3726. Google Scholar
}

DOI: 10.17151/rlef.2021.13.2.6. 


\title{
Reflections on changes in gender relations in families and fatherhood in Mexico
}

\begin{abstract}
Objective: The objective of this paper is to reflect on changes in gender relations in families and parenthood in Mexico. Methodology: Methodologically, documentary information between 1987 and 2020 was consulted. Classic texts that allow locating the changes in meanings around childhood and the relationship of parents with their children are incorporated, since the relationship, care and attention was not always considered a priority as it is today. Results: The results show how the cultural transformations based on the commitments assumed in the International Conference on Population and Development, and World Conferences on women, Mexico City (1975) and Beijing (1995), incorporate actions to involve men in gender equal rights and fatherhood. Conclusion: The conclusion suggests how involvement in families leads them to reconcile participation in various settings, building complex identities as men/couples/parents/workers.
\end{abstract}

Key words: gender, family, fatherhood, identity.

\section{Introducción}

Un compromiso social y político es reconocer los aportes de los movimientos feministas en los procesos de cambio y transformación en las familias —así en pluralporque existe más de una estructura y dinámica, que confronta perspectivas en torno a las nociones y significados de las funciones que deberían asumir las mujeres y los hombres a lo largo de su trayectoria de vida. Un caso particular es la paternidad que, como proceso sociocultural, va más allá del aspecto biológico.

Los cambios en las relaciones de género y la paternidad no pueden verse al margen de los compromisos establecidos en la Conferencia Internacional de Población y Desarrollo, celebrada en El Cairo (1994); y las conferencias mundiales sobre la mujer, que se celebraron en Ciudad de México (1975), Copenhague (1980), Nairobi (1985) y Beijing (1995), marcando un importante punto de inflexión para la agenda mundial de igualdad de género, cuestionando y analizando las condiciones en que los hombres asumían su papel como padres en los ámbitos familiares. De ahí, se tuvo que ampliar la discusión en torno a las familias, estableciéndose acuerdos para trabajar 
con los hombres en el logro de la igualdad de género. Enfatizar las responsabilidades de la crianza de los hijos y los quehaceres domésticos; promoviendo la participación activa en la paternidad responsable (Lerner, 1998; Barker y Verani, 2008; Herrera et al., 2018). La incorporación de los hombres que son padres como una cuestión social y no solo del ámbito privado de las familias, forma parte del carácter político.

En Latinoamérica se empiezan a identificar importantes cuestionamientos al modelo de familia tradicional y la paternidad. No obstante la transición del padre proveedor y figura de autoridad, hacia la relación cercana con los hijos se da lentamente, por lo que se ha dirigido el interés hacia la paternidad y su relación con los ámbitos de salud, educación y trabajo con vías a plantear políticas públicas (CEPAL, 2002). En México, se ha reforzado el cuestionamiento y análisis en temas relacionados con las familias, relaciones de género, los hombres y la paternidad. Aun cuando en algunos espacios públicos se siga perpetuando un modelo tradicional, cada vez son más los requerimientos por acceder a estructuras familiares que dignifiquen las relaciones de género.

El análisis que presenta el Centro de Estudios para el Adelanto de las Mujeres y la Equidad de Género (CEAMEG, 2007), considera que en algunos marcos legales y jurídicos perviven argumentos que aluden a la costumbre y tradición de la familia mexicana, sin considerar la diversidad de conformaciones familiares, lo cual tiene implicaciones en el reconocimiento de la igualdad de derechos de las mujeres y los hombres. En ocasiones no se consideran las responsabilidades que México suscribió respecto al tema de las familias y paternidad responsable, bajo argumentos centrados en la costumbre y la tradición, prevaleciendo sesgos de género en los códigos civiles estatales en materia de familias y paternidades responsables, restringiéndose a las obligaciones alimentarias y el reconocimiento de filiación.

La incorporación de los hombres en su ejercicio como padres más allá de la proveeduría económica, su implicación en el cuidado y la atención de sus hijos son aspectos no contemplados, siendo sumamente importantes en la procuración de justicia desde el marco de derechos para niños y mujeres mexicanas (CEAMEG, 2007).

Desde la perspectiva sociocultural de género, la paternidad forma parte de los procesos de interacción social, de las condiciones materiales de vida y normatividades institucionales, de manera que, como señala De Keijzer (2000), tendríamos que hablar de "paternidades" en plural, porque hay formas bastante diversas de ejercerla. Sin embargo, en México el interés históricamente se ha centrado en la maternidad y poco a poco se incorpora la paternidad, de manera que existe poca información sociodemográfica sobre los hombres en su ejercicio como padres, lo cual se debe en gran medida a la visión feminizada de la reproducción, donde la presencia de los hombres se asume como secundaria. 
El que no se haya documentado ampliamente sobre los hombres en su ejercicio como padres, no quiere decir que no se involucren o incluso que algunos sean los cuidadores directos de sus hijos. Lerner (1998), Figueroa et al. (2006), Maroto et al. (2009), Figueroa (2011), Figueroa y Salguero (2020) y Salguero y Yoseff (2020) consideran que existen diversas razones que explican la ausencia de estudios, como el énfasis que se ha otorgado a las mujeres como objeto de estudio ya que implícita o explícitamente la reproducción se ha asignado a las mujeres, y los hombres quedan al margen. Chodorow (1984) y Bowlby (1993) consideran que los argumentos se centran en la importancia de la madre como el primer y más importante objeto de vinculación con el hijo, lo cual ha permeado diversos ámbitos como la medicina y la psicología. Como ha señalado Parke (1986): "No es que nos olvidemos del padre por mero descuido o azar, sino que le ignoramos a propósito debido a nuestra creencia de que es menos importante que la madre en su influencia sobre el desarrollo del hijo" (p. 23).

Ha sido a partir de los cambios culturales en la estructura y organización de vida familiar que la participación de los hombres ha venido tomando lugar, ingresando a la corresponsabilidad de la vida íntima lo que para muchos no fue nada fácil.

Desde los diversos ámbitos de investigación se tuvo que hacer un acercamiento a la vida íntima de las familias, para dar cuenta del papel de los hombres como padres en la relación con sus hijos y compañeros en la relación de pareja, requiriendo abordajes teórico-metodológicos que permitieran conceptualizar a los hombres como padres.

Documentar que el orden de género (Connell, 2003) históricamente ha formado parte de arreglos y prácticas socioculturales como la maternidad y la paternidad (Lagarde, 1993), con desigualdades sociales de género (HernándezRosete, 1996; Nava, 1996; Figueroa, 1999; Alatorre y Luna, 2000; Fuller, 2000; Gutmann, 2000; Rojas, 2000; Salguero, 2002; Núñez, 2007). Parte importante del trabajo teórico-metodológico incorporó el carácter relacional de género en el proceso de construcción de las identidades masculinas desde las relaciones de poder, libertad, sexualidad, ausencia de emociones y sentimientos, preocupación constate por el trabajo pero, a su vez, la posibilidad de ser padres, de reconstruirse como hombres en la relación compartida con sus hijos (Gutmann, 1998, 2000; Salguero, 2008; Figueroa y Salguero, 2020; Salguero y Yoseff, 2020).

La paternidad forma parte de una construcción sociocultural e histórica, por lo que sus significados serán distintos entre culturas, etnias, niveles económicos y educativos (Fuller, 2000); o en un mismo hombre dependiendo de la edad, momento y condiciones en las que se llega a ser padre, por lo que no se puede hablar de la paternidad en singular sino de formas distintas de ser padre aludiendo al carácter procesual (Salguero y Pérez, 2011a; Roopnarine, 2013; Figueroa y Salguero, 2020), que den cuenta de los cambios en las familias y la paternidad, donde los hombres han 
Reflexiones sobre los cambios en las relaciones de género en las familias...

tenido que aprender y re-aprender a partir de la relación compartida con la pareja y los hijos (Gutmann, 2000; Rojas, 2007; Jiménez, 2013).

\section{Metodología}

El proceso reflexivo se llevó a cabo a partir de una investigación documental con 68 textos que permitieran dar cuenta de nuestro objeto de estudio: cambios o transformaciones en las relaciones de género, familias y paternidades. Se incorporó la revisión sistemática de material bibliográfico resultado del proceso de investigación en ciencias sociales (Jiménez, 2006), el cual posibilita la elaboración y construcción de nuevos sentidos y significados en torno al objeto de estudio (Guevara, 2016), en nuestro caso las relaciones de género, familias y paternidades. Se consideró la propuesta de Fink (2014), para la revisión teórica a nivel documental y la búsqueda en las bases de datos como Redalyc, Latindex, Doaj, Dialnet, Pubmed, Academia, Ebsco y Clacso. Si bien se priorizó información de Latinoamérica durante el período de 1990 a 2020 con la finalidad de reconocer la producción científica de nuestro continente, también se incluye información de otros espacios geográficos, así como tesis de posgrado en cuanto a nivel de especialización en el tema de paternidad.

Con la finalidad de dar respuesta a nuestro objetivo al abordar los cambios en las paternidades, los procesos de involucramiento y participación de los padres, se consideró necesario situar históricamente el proceso, por lo que se recurrió a la revisión de textos clásicos como: El niño y la vida familiar en el antiguo régimen (Ariès, 1987); El Ejercicio de la maternidad. Psicoanálisis y sociología de la maternidad y paternidad en la crianza de los hijos (Chodorow, 1984); Historia de la Infancia (DeMause, 1994). Para dar cuenta de los cambios en los significados a través de la historia en torno al papel de los hijos y la relación de los padres, así como también información de la UNICEF. Se priorizó la voz en el ámbito de la investigación de los expertos en el tema.

El desarrollo de este artículo integra los siguientes ejes de análisis: 1) Cambios en la estructura y dinámica familiar; 2) Transiciones de la paternidad en México; 3) El papel de los hombres como padres; 4) Involucramiento paterno y desarrollo de los hijos; 5) Construyendo identidad como padre en la práctica: implicación socioemocional en la vida de los hijos; 6) Identidades complejas: esposa/madre/ trabajadora y esposo/padre/trabajador.

\section{Resultados}

\section{Cambios en la estructura y dinámica familiar}

En México, a nivel gubernamental fue en 2000 cuando se integraron indicadores para reunir información sobre los hombres y la paternidad a través del 
Instituto Nacional de Estadística, Geografía e Informática (INEGI). La información aún es poca, sin embargo se puede tener un acercamiento a partir del contexto sociocultural, conformación familiar, situación de conyugalidad e hijos. Los datos que se presentan forman parte del Censo de 2010 (INEGI, 2010) publicados en 2013, identificándose un descenso de la tasa global de fecundidad, comparativamente con la década del 60 donde el ritmo de crecimiento de la población fue en aumento llegando a 6,5 hijos, y en 2010 de 2,2 hijos por familia. Esto a partir de varios factores entre los que se pueden mencionar: la modificación del Artículo $4^{\circ}$ constitucional en 1973, con lo que se establece el derecho a decidir de manera libre, responsable e informada el número de hijos y el momento de tenerlos; la puesta en marcha de políticas gubernamentales y del sector salud para regular la fecundidad; campañas en los medios de comunicación difundiendo discursos como "la familia pequeña vive mejor", "ser pocos para darles más", invitando o incitando a la población a "tener menos hijos"y regular su reproducción a través del uso de métodos de anticoncepción. Actualmente, el porcentaje de mujeres unidas en edad fértil y usuarias de métodos anticonceptivos es de 72,5\%, lo cual es significativo.

En relación con los sistemas de unión, se encuentran cambios en los patrones de nupcialidad: el inicio de la vida en pareja se ubica entre los 20 y 30 años. La mayoría de los hombres a partir de los 25 años prefieren vivir en pareja, con mayor peso relativo de los 35 a 69 años y las mujeres de los 30 a 74 años, quienes mayoritariamente son casadas o unidas. En México sigue predominando la población casada. El matrimonio civil y religioso ha sido una práctica socialmente legitimada para la unión de parejas, sin embargo, se ve reemplazada gradualmente por el matrimonio civil o la unión libre legalizándose en el curso del tiempo y duplicándose de 7,4 a 14,4\%. Quilodrán (2001) y Vassallo (2011) plantean que la 'unión libre' en el contexto latinoamericano se refiere a la unión conyugal y constituye una forma de hacer familia sin pasar por el trámite legal del Registro Civil, ni por la Iglesia; la población casada o unida vive o comparte la vivienda con su pareja conyugal en un 95,4\%.

Un dato importante es que se ha triplicado la proporción de separados o divorciados de 1,9 a 5,2\%, lo cual representa transformaciones en las formas de unión y permanencia de la vida en pareja. Las diferencias de género, edad, motivaciones y expectativas han generado conformaciones distintas como familias monoparentales, reconstituidas de segundas o terceras nupcias, viviendo juntos pero separados, relaciones de pareja sin considerar la cohabitación compartida; y familias homoparentales, las cuales no están documentadas, pues en noviembre de 2006 fue aprobada la Ley de Sociedades de Convivencia, y el 21 de diciembre de 2009 la Asamblea Legislativa del Distrito Federal, ahora Ciudad de México, aprobó el matrimonio entre personas del mismo sexo, entrando en vigor en marzo de 2010. Aun cuando se presentan nuevas conformaciones familiares, en México sigue predominando la familia nuclear 
en $64,2 \%$ del conjunto total de la población; la composición más común es la pareja conyugal con hijos.

En la estructura de los hogares mexicanos, el mayor porcentaje corresponde a jefatura masculina $(56,4 \%)$ y el papel de cónyuge es desempeñado casi en su totalidad por mujeres. Tanto el hombre como la mujer desempeñan un conjunto de actividades organizadas a través de una primaria división sexual del trabajo al interior del hogar. Los hombres en tanto jefes de familia se dedican a actividades laborales, 91 de cada 100 realizan una actividad económica, predominando la producción de bienes y servicios, por lo que el rol social es de proveedor del hogar. En cuanto a las mujeres como cónyuges, el 68,8\% realiza actividades domésticas, cuidado de la vivienda y crianza de los hijos que permiten la reproducción cotidiana del grupo familiar; el 31,2\% desempeña una actividad económica pero además realiza actividades domésticas enfatizando y reforzando los roles de género tradicionales.

La jornada laboral para los hombres se encuentra entre 35 y 48 horas semanales, el 42,2\% trabaja más de 48 horas, lo cual en muchas ocasiones no se ve y se naturaliza; es común que los integrantes de las familias pasen la mayor parte de su tiempo en sus ámbitos de trabajo. Es interesante observar cómo las formas de estructura y dinámica familiar siguen siendo productoras de valores y significados como la armonía, solidaridad, seguridad, cuidado y negociación, pero también por jerarquías, expresiones de dominio, autoridad y en ocasiones subordinación por género y edad (Salles y Tuirán, 1998; Ariza y De Oliveira, 2004; García y De Oliveira, 2006; Rabell, 2009).

\section{Transiciones de la paternidad en México}

En México, las actividades y formas de relación que establecen los padres con sus hijos incorporan algunos cambios en comparación con la generación de sus propios padres; se encuentran más presentes en las actividades de la casa y tareas con sus hijos, incorporan el diálogo, la cercanía, el juego, manifestación de emociones y sentimientos, lo cual no ha sido igual a lo largo del tiempo. Como indica Knibiehler (1997):

En cada viraje de la civilización, en el pasado, hubo nuevos padres, de manera tal que se han incorporado significados, modelos e imágenes del padre que forman parte del sistema social, político e ideológico históricamente constituido en el que se organiza la actividad de los hombres como padres. (p. 117)

Históricamente se pueden identificar dos modelos, de acuerdo con Rabell (2009), el patriarcal caracterizado por ser autoritario, rígido y jerárquico, y el relacional, 
más igualitario, democrático y flexible, transitando de un esquema de respeto a otro de confianza.

Se puede plantear que los cambios no son totales ni se dan de un momento a otro, por lo que es preferible documentar transiciones o desplazamientos como menciona Esteinou (2004):

\begin{abstract}
Cuando hablamos de cambios enfrentamos una tarea difícil no sólo por las distintas definiciones, sino también por el grado de intensidad y dirección de éstos. En las prácticas de paternidad podemos presenciar cambios y continuidades al mismo tiempo, por ejemplo, un hombre puede participar en las actividades con sus hijos y no responsabilizarse de las actividades del hogar. La participación con sus hijos implica un cambio a partir del modelo tradicional, pero puede ser subvalorado en tanto no es coparticipe de las actividades del hogar. (p. 253)
\end{abstract}

Nos enfrentamos a cambios y al mismo tiempo continuidades en las actividades de los hombres como padres. Gutmann (2000) y Rojas (2007) presentan resultados de investigaciones con hombres de diferentes sectores socioeconómicos; los entrevistados refieren que en sus familias de origen la estructura de participación de los hombres era tradicional, la madre se ocupaba del trabajo doméstico y el padre de la provisión de ingresos para el sustento familiar. En tanto que, en autoridad y disciplina, algunos padres mencionan que ya no pueden imponer, solo sugerir, pues si llegaran a amenazar, castigar o golpear, las parejas y los hijos intervienen y marcan los límites de la actuación del padre (Salguero, 2002). Se usa más el diálogo y la explicación, lo cual es reforzado por las instituciones escolares, quienes imparten conferencias y cursos como parte del programa de "Escuela para padres" que incluye algunas técnicas disciplinarias, establecimiento de límites y seguimiento de reglas.

Se pueden identificar algunas transiciones en la forma de ejercer la paternidad con sus hijos. Algunos refieren que no desean repetir la historia vivida con su padre, esforzándose por ser más flexibles y expresivos, ya que en la actualidad 'no es suficiente con ser padre, ahora hay que ser un buen padre', y eso es complicado porque no hay un guion que les indique cómo hacerlo; se va ensayando en la relación familiar.

\title{
E1 papel de los hombres como padres
}

Un punto importante es cómo a partir de las estructuras y dinámicas familiares, la reorganización de las relaciones entre hombres y mujeres ha incorporado cambios en la identidad de los hombres como padres.

Figueroa (1998) analizó los resultados de la Encuesta sobre Comportamiento, Actitud y Práctica Anticonceptiva de la Población Obrera (Encapo), encontrando que los hombres reconocen como responsabilidad principal la familia, mantener a 
Reflexiones sobre los cambios en las relaciones de género en las familias...

los hijos y a la mujer, sin embargo, más de la mitad no estaba de acuerdo en que la mujer trabajara fuera del hogar porque lo descuidaba, porque no atendía a los hijos, porque podría ser infiel y porque a ellos les correspondía trabajar y proveer. Estos datos coinciden con el análisis sobre dinámicas de vida familiar propuesto por Ariza y De Oliveira (1999), indicando que los hombres de diferentes sectores sociales siguen distinguiendo su rol de proveedores; se reconoce el ingreso de las mujeres como parte importante aunque sin reconocimiento social, permaneciendo la creencia de que las mujeres que realizan una actividad laboral fuera del hogar tienden a descuidar la casa y los hijos.

No obstante, las mujeres han permanecido en la lucha por sus derechos, muchas desde la militancia política, otras desde la cotidianidad de los espacios domésticos. Investigaciones como las de Benería y Roldán (1992), García y De Oliveira (1994) y Casique (2004) dan evidencia de que el trabajo remunerado genera cambios importantes en la identidad de las mujeres al reconocerse con mayor poder de decisión, libertad de movimiento, desarrollo de autonomía y autoestima, lo cual transforma las prácticas cotidianas en el espacio doméstico requiriendo la participación de los hombres en su función de padres. García y De Oliveira (2006) encontraron arreglos en cuanto a tiempo, actividades domésticas, cuidado y crianza de los hijos por parte de ambos cónyuges. Sin embargo, sigue existiendo una constante, una gran proporción de mujeres que trabajan y obtienen ingresos económicos llevan a cabo las labores de organización del hogar, crianza y educación de los hijos (García y De Oliveira, 1994; Montiel et al., 2009) generando, en ocasiones, cansancio, desesperación y angustia que llevan a desencadenar conflictos en las relaciones de género entre las parejas.

En familias de doble ingreso donde ambos trabajan es notable el apoyo de redes familiares, sobre todo de abuelas, tías u otros familiares; algunas recurren al servicio de guarderías o estancias infantiles cuando los hijos son pequeños, o pagan horas extras en algunas escuelas privadas como 'apoyo a la realización de tareas escolares' para que los atiendan durante el tiempo que ellos permanecen fuera del hogar por cuestiones laborales.

Esto coincide con el planteamiento de Ospina-García (2020), quien llevó a cabo una investigación en Colombia para dar cuenta de algunos cambios en las formas de implicación de los padres en el cuidado y crianza de sus hijos, aludiendo, a su vez, al apoyo que reciben de las redes familiares y de amigos. Ospina-García considera que: "Este proceso es reconocido ya que son las familias quienes intercambian materiales y recursos económicos a otras personas para delegar el cuidado por un período determinado de tiempo" (p. 177).

Los padres de familia, en su gran mayoría, se han enfrentado a una situación donde las formas tradicionales en las que aprendieron a ser padres han cambiado. Ahora tienen que compartir las responsabilidades del hogar y las decisiones familiares, por lo que cada vez más se han visto en la necesidad de cambiar como 
hombres y padres (Salguero, 2007; Rojas, 2007; Saldaña y Salgado, 2018; Figueroa y Salguero, 2020).

\section{Involucramiento paterno y desarrollo de los hijos}

El involucramiento paterno forma parte de los cambios en el ámbito de la paternidad y dinámicas familiares. Se va construyendo en la relación de pareja, desde el momento que se plantea la posibilidad de tener un hijo, elaborando el proceso de decisión del embarazo que cambiará sus vidas. Las formas de convivencia, acompañamiento, actividades y tiempos de involucramiento son diferentes en función de la trayectoria y momentos del desarrollo de los hijos, cuando son pequeños, adolescentes o adultos (Hernández-Rosete, 1996; Nava, 1996; Rojas, 2000; Torres, 2002; Astone y Peters, 2014; Salguero y Yoseff, 2020).

Los procesos de involucramiento de los padres en muchas ocasiones son mediados por la participación de las mujeres. Gutmann (2000), Haces (2006), Salguero y Pérez (2011b) y Ospina-García (2020) consideran que las mujeres han jugado un importante papel para que los hombres se involucren en la paternidad, cuestionándolos por su poca o nula participación y marcando posturas que les han llevado a negociar la continuidad de la relación siempre y cuando ellos cambien sus formas de participación en el ejercicio como padres, dedicando tiempo a sus hijos en las diversas actividades de la vida diaria.

El involucramiento paterno en el desarrollo socioemocional e intelectual de los niños se refleja en mejores notas y bajos índices de sanciones disciplinarias o de reprobación escolar (Barker y Verani, 2008; Ortega et al., 2011).

La presencia e implicación paterna no solo favorece el desarrollo de los hijos, sino también la salud física y emocional de la madre y el propio padre. En las familias donde se ha construido una buena relación, negociado y acordado formas de participación equitativas, se encuentran mejores condiciones para el buen vivir. Los padres involucrados en la relación con el hijo pueden desarrollar habilidades como la empatía, tolerancia y consideración, y fueron investigados por Ruiz (1997), quien realizó una serie de entrevistas en las que encontró que en su discurso los hombres ubican el proceso de paternidad como bidireccional, pues se sienten bien cuando los hijos les muestran afecto, se sientan orgullosos y buscan estar con ellos y ellas como padres.

\section{Construyendo identidad como padre en la práctica: implicación socioemocional en la vida de los hijos}

Uno de los cambios y transiciones importantes de los hombres en las prácticas de paternidad es la implicación socioemocional en la vida de los hijos, pues, como 
Reflexiones sobre los cambios en las relaciones de género en las familias...

plantea Figueroa (2000), la paternidad puede verse como el conjunto de relaciones posibles que pueden darse entre un progenitor y sus hijos, sin reducirla a una cuestión biológica. Las relaciones pueden ser de afecto, cuidado y conducción, a la vez que de sostén económico, autoridad, amor y diversión conjunta, de los acuerdos familiares sobre las dinámicas de relación entre sus integrantes.

El que actualmente se ponga atención en las formas de implicación del padre con sus hijos tiene que ver con la importancia otorgada a la niñez, lo cual nos obliga a situar históricamente pues en el pasado no había una preocupación tan grande por los niños y podían vivir sin los cuidados exhaustivos de la madre o el padre (Ariès, 1987). Es a partir del concepto moderno de niñez que se vuelve motivo de atención el desarrollo infantil, el futuro del niño; su presencia y existencia ocupa un lugar central en la familia, instituciones de salud y educativas. Su desarrollo, necesidades y bienestar se han diversificado y expandido de manera que las tareas ligadas a la paternidad resultan cada vez más difíciles y complejas.

El sentido y significado otorgado a la infancia, maternidad y paternidad se han visto influenciados por discursos institucionales, teorías y opinión de "expertos" generando una profesionalización y tecnologización de la función paterna. Las relaciones entre los padres y sus hijos se convirtieron en objeto de la ciencia, la medicina, la pediatría y la psicología, representantes del curso del desarrollo. DeMause (1994) ha planteado que los conceptos de "socialización infantil" y "ayuda" surgen a mediados del siglo XX donde se propone que al niño había que enseñarlo, capacitarlo, guiarlo en cada etapa de la vida. Salinas (2002) y Cillero (2007) destacan que, además de mostrar un interés, había que reconocer el derecho de todos los niños a la oportunidad de un desarrollo no nada más físico sino intelectual, emocional, social y el derecho a ser tratados con dignidad y respeto.

Con la aprobación de la Convención sobre los Derechos del Niño (CDN) en 1989, se consolida y difunde una cultura de la atención al niño, con base en los derechos básicos, civiles y de protección a la infancia, acordados en la Constitución Política de los Estados Unidos Mexicanos, Art. 40; Ley para la Protección de los Derechos de Niñas, Niños y Adolescentes, Art. 11; y organismos internacionales (CEPAL, 2002; UNICEF, 2007).

La investigación sobre paternidad en México se ha dirigido a los hombres en el proceso de construcción de identidad como padres, encontrando que despliegan formas de participación que van más allá de la proveeduría económica, siendo co-partícipes del proceso de desarrollo de sus hijos (Jiménez, 2003; Haces, 2006; Rojas, 2006; Salguero, 2006; Salguero y Yoseff, 2020), muestran diversas formas de ser y hacer de los hombres, identifican la complejidad que actualmente representa ser padre; no basta con proveer y ser figura de autoridad, también hay que compartir tiempo con la pareja y los hijos, estar al tanto de sus necesidades, 
compartir actividades en el hogar, implicarse emocionalmente, ser cariñoso, mostrar emociones y sentimientos, lo cual se les dificulta al no contar muchas veces con experiencias cercanas, afectivas o lúdicas sobre paternidad ya que en muchos casos lo vivido con sus propios padres fue la distancia, ausencia, violencia o rechazo.

Construir identidad como padre implica asumir nuevas responsabilidades y compromisos, participar en un proceso de aprendizaje constante, creando historias de compromiso mutuo, de responsabilidad compartida (Holland et al., 1998). Esforzándose por encontrar referentes para poder llevar a cabo su papel como padres en situaciones muchas veces desconocidas como lo han documentado Salguero y Pérez (2008).

El aprendizaje a través de las actividades diarias con los hijos permite que un hombre pueda construir identidad como padre. Lave y Wenger (2003) consideran las oportunidades de aprendizaje más que las acciones propiamente de enseñanza. Será a través de las relaciones entre la madre, el padre y los hijos como se irá construyendo la identidad como padre en la práctica; aprenden resolviendo problemas cotidianos, en la co-contrucción con los otros integrantes. No solo la madre y el padre influyen/ orientan/dirigen el desarrollo de los hijos, sino que también los hijos influyen a su vez en el desarrollo de los padres y madres. Es en el proceso relacional como los padres aprenden a ser más tolerantes, a escuchar y resolver problemas, señalando que 'sus hijos los han cambiado como padres'.

\section{Identidades complejas: esposo/padre/trabajador}

A partir de la confrontación de las formas familiares tradicionales se han tenido que negociar actividades y tiempos para conciliar las exigencias de vida laboral y familiar, reconociendo las necesidades tanto de mujeres como de varones no solo por el bienestar familiar, sino también el desarrollo personal y profesional. Lo cual ha llevado a construir identidades complejas como madre/esposa/trabajadora y a su vez como padre/esposo/trabajador, las cuales se entrecruzan y desplazan entre sí, pero situándose en la misma persona, desarrollando habilidades para organizar sus tiempos, actividades, emociones y afectos (Salguero, 2013). Transitado de una práctica de paternidad donde históricamente afirmaba la masculinidad y el control familiar hacia una participación donde la relación con los hijos, la pareja y el trabajo resultan importantes, es en la articulación de las diferentes formas de participación donde se va construyendo la identidad como padre. Conduciendo su vida, tratando de ser y estar ahí como hombre/pareja/padre/trabajador. Es probable que algunos dediquen más interés al ámbito laboral, en tanto que para otros lo fundamental será estar con la familia y los hijos, construyendo diversas formas de identidad en la práctica como hombres/padres/trabajadores (Salguero y Pérez, 2011a). 
Reflexiones sobre los cambios en las relaciones de género en las familias...

Los padres que se esfuerzan por ser diferentes muchas veces son criticados hasta por sus propios familiares y amigos cercanos, por transgredir lo que se espera socialmente de un hombre y un padre desde el "deber ser" instituido y caracterizado por los estereotipos de género, según los cuales no deberían estar tanto tiempo con la familia y los hijos, ni participar en la limpieza del hogar. Intentar ser un hombre y un padre diferente cuestiona el "deber ser" desde los estereotipos de género, llevándolos a un proceso constante de negociación de sus identidades como hombre/padre/trabajador.

Es necesario documentar el proceso de construcción de las múltiples identidades como hombre y padre, confrontar esa visión homogénea de los "hombres o los padres en México", colocando el punto de interés en el carácter procesual, en las condiciones particulares en las que se vive y construye la identidad como padre. A través de las actividades y formas de relación con los hijos (Nava, 1996; Gutmann, 2000; Esteinou, 2004; García y De Oliveira, 2004), analizando la diversidad de formas en las que un hombre ejerce como padre (De Keijzer, 2000), identificando significados y prácticas de la paternidad (Alatorre y Luna, 2000; Salguero, 2002), mostrando diferencias en la crianza de hijos (Torres, 2002), analizando formas particulares de paternidad con hijos con discapacidad (Ortega et al., 2011); sexualidad, reproducción y paternidad (Jiménez, 2003); siendo padres, esposos e hijos (Figueroa et al., 2006); abordando los dilemas y conflictos en el ejercicio de la maternidad y la paternidad (Salguero y Pérez, 2011a); de las presencias y ausencias paternas (Salguero y Yoseff, 2020); para dar cuenta de las diversas aristas en la paternidad (Figueroa y Salguero, 2020).

\section{Conclusión}

La reflexión sobre las relaciones de género, familias y paternidades tendría que retomar los compromisos establecidos en la Conferencia Internacional sobre Población y Desarrollo del Cairo (1994) y las conferencias mundiales de la mujer, donde se plantea un proceso de re-significación de las relaciones de género y, a su vez, un análisis en las formas de involucramiento de los hombres en su papel de padres para lograr relaciones de género en el ámbito de las familias más equitativas e igualitarias.

Reconocer que en este momento histórico es imprescindible el trabajo y la investigación sobre los hombres, las masculinidades y paternidades, desde una perspectiva sociocultural de género, promoviendola participación activa de los hombres en los ámbitos de la paternidad, bajo un sentido de responsabilidad, involucramiento y acompañamiento amoroso con los hijos y la pareja en la construcción de familias desde una conceptualización del buen trato, como un asunto social y no privado.

Ha sido necesario abordar los procesos de transición, pero a su vez las continuidades en las familias y la paternidad en México ya que los cambios no son 
totales ni se dan de un momento a otro, por lo que es preferible hablar de transiciones o desplazamientos como menciona Esteinou (2004). Un caso particularmente importante es la paternidad a partir de los cambios en la estructura y dinámica familiar, en el caso de México es realmente reciente, pues a partir de 2000 es cuando se integran indicadores para reunir información sobre los hombres y la paternidad, abriendo un sendero de reflexión y conocimiento sobre el tema.

Hablar de los hombres como padres implica abordar el carácter relacional de género en las relaciones entre hombres y mujeres en los procesos de construcción de la identidad; enfrentado a la necesidad de cambiar las formas a través de las cuales aprendieron a ser hombres y a ser padres, con estereotipos de género centrados en el poder control y desigualdad, siendo cuestionados por la pareja o los hijos (Rojas, 2007; Salguero, 2007; Saldaña y Salgado, 2018).

Fue necesario abordar los procesos de paternidad, plantear esos pequeños y a su vez grandes cambios en las formas de relación de los padres en las familias, las actividades del hogar y tareas con sus hijos, incorporan el diálogo, la cercanía, el juego y la manifestación de emociones y sentimientos, aprendiendo a cuidar de los hijos y la pareja como ha señalado Ospina-García (2020). Intentando ser hombres y padres diferentes a sus propios padres, no repitiendo la misma historia. Llevándolos a un proceso de involucramiento como padres en la relación con sus hijos, a través del trato diario, del cuidado, de la atención y el tiempo compartido. Esto, en gran medida, generado a partir de ese carácter relacional de género donde las parejas van requiriendo otras formas de participación como hombres y padres. Y una vez que se empiezan a involucrar no solo favorecen el desarrollo de los hijos, sino que también tiene implicaciones en su vida y salud física y emocional de la madre y el propio padre.

Los esfuerzos en los procesos de cambio e involucramiento paterno permiten construir identidad como padre en la práctica, algo que históricamente no se había contemplado, porque la preocupación por el desarrollo y bienestar de los niños es reciente. Ariès (1987) y DeMause (1994) lo han descrito y situado en los momentos históricos, de manera que los conceptos sobre la implicación paterna y el desarrollo infantil se plantean a mediados del siglo XX. Además de mostrar interés, había que reconocer las necesidades $y$, sobre todo, los derechos de todos los niños a la oportunidad de vivir en un ambiente sano y que propicie un desarrollo no solo físico sino también emocional, con dignidad y respeto. Y ahí es donde la implicación de los padres tiene un lugar preponderante, siendo co-partícipes de esa enorme responsabilidad.

Los hombres construirán identidad como padres a través del proceso continuo de aprendizaje, donde incorporen los diferentes ámbitos de participación, el trabajo, la casa, la pareja y los hijos, de manera que construirán identidades complejas como esposa/madre/trabajadora y esposo/padre/trabajador, dedicando los tiempos y formas de participación, no siendo solo proveedores sino también 
Reflexiones sobre los cambios en las relaciones de género en las familias...

incorporando, a su vez, otras formas de participación y compromiso en casa, con la familia, la pareja y los hijos.

Atreviéndose a ser un padre diferente aun cuando atente contra los estereotipos establecidos y le genere incertidumbre; será en la relación compartida donde construirán otras maneras de ser hombre y padre, en la entrega y reconocimiento de la pareja y los hijos a través del tiempo, la atención y amor compartido, quedando en sus vidas a lo largo de sus historias.

\section{Referencias}

Alatorre, J. y Luna, R. (2000). Significados y prácticas de la paternidad en la ciudad de México. PUEGUNAM.

Ariès, P. (1987). El niño y la vida familiar en el antiguo régimen. Taurus.

Ariza, M. y De Oliveira, O. (1999). Trabajo, familia y condición femenina: una revisión de las principales perspectivas de análisis. Universidad Autónoma de Estado de México.

Ariza, M. y De Oliveira, O. (2004). Universo familiar y procesos demográficos. En M. Ariza y O. De Oliveira (Coords.). Imágenes de la familia en el cambio de siglo (pp. 9-45). UNAM.

Astone, N. M. y Peters, H. E. (2014). Longitudinal influences on men's lives: Research from the transition to fatherhood Project and beyond. Fathering, 2, 161-177.

Barker, G. y Verani, F. (2008). La participación del hombre como padre en la región de Latinoamérica y el Caribe: una revisión de literatura crítica con consideraciones para politicas. Promundo-Save the Children.

Benería, L. y Roldán, M. (1992). Las encrucijadas de clase y género. Trabajo a domicilio, subcontratación y dinámica de la unidad doméstica en la ciudad de México. El Colegio de México.

Bowlby, J. (1993). El vinculo afectivo. Paidós.

Casique, I. (2004). Trabajo femenino, empoderamiento y bienestar de la familia. Editado por UCSD Center for U.S.-Mexican Studies. Latin American Studies Association, USA.

CEAMEG. (2007). Colección Género y Derecho. H. Cámara de Diputados, México: Autor. www3. diputados.gob.mx/camara/CEAMEG

CEPAL. (2002). Propuesta de indicadores de paternidad responsable. Educación reproductiva y paternidad responsable en el Istmo Centroamericano. CEPAL.

Chodorow, N. (1984). El ejercicio de la maternidad. Psicoanálisis y sociología de la maternidad y paternidad en la crianza de los hijos. Edit. Gedisa.

Cillero, M. (2007). El interés superior del niño en el marco de la Convención Internacional sobre los Derechos del Niño. http://www.observatoriosocial.com.ar/proyectos/proelinteres.pdf

Connell, R. (2003). Masculinidades. PUEG, UNAM.

De Keijzer, B. (2000). Paternidades y transición de género. En N. Fuller (Comp.). Paternidades en América Latina (215-240). Pontificia Universidad Católica del Perú. 
DeMause, L. (1994). Historia de la infancia. Alianza.

Esteinou, R. (2004). La parentalidad en la familia: cambios y continuidades. En M. Ariza y O. De Oliveira (Coords.). Imágenes de la familia en el cambio de siglo (pp. 251-281). UNAM.

Figueroa, J. G. (1998). La presencia de los varones en los procesos reproductivos; algunas reflexiones. En S. Lerner (Ed.). Varones, sexualidad y reproducción (pp. 163-189). El Colegio de México.

Figueroa, J. G. (1999). Fecundidad, anticoncepción y derechos reproductivos. En B. García (Coord.). Mujer, género y población en México (pp. 61-101). E1 Colegio de México.

Figueroa, J. G. (2000). Algunos elementos del entorno reproductivo de los varones al reinterpretar la relación entre salud, sexualidad y reproducción. Revista Mujer Salud, Santiago de Chile, Red de salud de las mujeres latinoamericanas y del Caribe, 3, 60-72.

Figueroa, J. G. (2011). Paternidad, mortalidad y salud: ¿es posible combinar estos términos? En Estudios sobre varones y masculinidades para la generación de politicas públicas y acciones transformadoras (pp. 71-78). IV Coloquio Internacional de Estudios sobre Varones y Masculinidades. UNFPA-ONU.

Figueroa, J. G., Jiménez, L. y Tena, O. (2006). Introducción. Algunos elementos del comportamiento reproductivo de los varones. En J. G. Figueroa, L. Jiménez y O. Tena (Eds.). Ser padres, esposos e hijos: prácticas y valoraciones de varones mexicanos (pp. 9-53). El Colegio de México.

Figueroa, J. G. y Salguero, M. A. (2020). Nuevas aristas en el estudio de la paternidad. El Colegio de México.

Fink, A. (2014). Conducting research literature revierws. Sage publications.

Fuller, N. (2000). Significados y prácticas de paternidad entre varones urbanos del Perú. En N. Fuller (Ed.). Paternidades en América Latina (pp. 35-90). Pontificia Universidad Católica del Perú, Fondo Editorial.

García, B. y De Oliveira, O. (1994). Trabajo femenino y vida familiar en México. Colegio de México.

García, B. y De Oliveira, O. (2004). El ejercicio de la paternidad en el México urbano. En M. Ariza y O. De Oliveira (Coord.). Imágenes de la familia en el cambio de siglo (pp. 283-318). UNAM.

García, B. y De Oliveira, O.(2006). Las familias en el México metropolitano. Visiones femeninas y masculinas. El Colegio de México.

Guevara, P. R. (2016). El estado del arte en la investigación: ¿análisis de los conocimientos acumulados o indagación por nuevos sentidos? Revista Folios, 44, 165-179.

Gutmann, M. (1998). El machismo. Masculinidades y equidad de género en América Latina. En T. Valdés y J. Olavarría (Eds.). Masculinidades (pp. 238-257). FLACSO.

Gutmann, M. (2000). Ser hombre de verdad en la Ciudad de México. Ni macho ni mandilón. El Colegio de México.

Haces, M. A. (2006). La vivencia de la paternidad en varones del Valle de Chalco. En J. G. Figueroa, L. Jiménez y O. Tena (Eds.). Ser padres, esposos e hijos: Prácticas y valoraciones de varones mexicanos (pp. 121-155). El Colegio de México.

Hernández-Rosete, D. (1996). Género y roles familiares: la voz de los hombres (tesis de maestría). Centro de Investigaciones y Estudios Superiores en Antropología Social, México. 
Reflexiones sobre los cambios en las relaciones de género en las familias...

Herrera, F., Aguayo, F. y Goldsmith J. (2018). Proveer, cuidar y criar: evidencias, discursos y experiencias sobre paternidad en América Latina. Revista Latinoamericana, 50, 5-20. https://scielo.conicyt.cl/ pdf/polis/v17n50/0718-6568-polis-17-50-00005.pdf

Holland, D., Lachicotte, W., Skinner, D. y Cain, C. (1998). Identity and agency in cultural worlds. Harvard University Press.

Instituto Nacional de Estadística, Geografía e Informática. (2010). Censo de población y vivienda. http//www.inegi.gob.mx

Jiménez, A. (2006). El estado del arte en la investigación en las ciencias sociales. En A. Jiménez y A. Torres (Comps.). La práctica investigativa en ciencias sociales (pp. 27-42). Universidad Pedagógica Nacional.

Jiménez, M. L. (2003). Dando voz a los varones. Sexualidad, reproducción y paternidad de algunos mexicanos. UNAM, CRIM.

Jiménez, M. L. (2013). Reflexiones sobre ser proveedor en la crisis económica y del empleo. Impactos desde la perspectiva de género. En J. C. Ramírez y J. C. Cervantes (Coords.). Los hombres en México. Veredas recorridas y por andar (pp. 53-70). CUCEA-AMEGH.

Knibiehler, I. (1997). Padres, patriarcado, paternidad. En S. Tubert (Ed.). Figuras del padre (pp. 117-135). Ediciones Cátedra.

Lagarde, M. (1993). Los cautiverios de las mujeres: madresposas, monjas, putas, presas y locas. UNAM.

Lave, J. y Wenger, E. (2003). Aprendizaje situado. Participación periférica legítima. UNAM/FES Iztacala.

Lerner, S. (1998). Participación del varón en el proceso reproductivo: recuento de perspectivas analíticas y hallazgos de investigación. En S. Lerner (Ed.). Varones, Sexualidad y reproducción (pp. 9-46). El Colegio de México.

Maroto, G., Castaño, E., García, M., Hidalgo, N. y Mateo, I. (2009). Paternidad y servicios de salud. Estudio cualitativo de las experiencias y expectativas de los hombres hacia la atención sanitaria del embarazo, parto y posparto de sus parejas. Revista Española de Salud Pública, 83(2), 267-278.

Montiel, P., Salguero, A. y Pérez, G. (2009). El trabajo: ¿̨uente de conflicto en el ejercicio de la paternidad? Psicología y Ciencia Social, 10(1), 26-40.

Nava, R. (1996). Los hombres como padres en el Distrito Federal a principios de los noventa (tesis de maestría). FCPyS UNAM.

Núñez, G. (2007). Vínculo de pareja y hombría: "atender y mantener" en adultos mayores del Río Sonora, México. En A. Amuchástegui e I. Szasz (Coords.). Sucede que me canso de ser hombre... Relatos y reflexiones sobre hombres y masculinidades en México (pp. 141-184). El Colegio de México.

Ortega, P., Torres, L. y Salguero, A. (2011). Parenthood and Social Evaluation of Special Children. International Journal of Hispanic Psychology, 3(2), 283-292.

Ospina-García, A. (2020). Nuevas masculinidades y cambio familiar: repensando el género, los hombres y el cuidado infantil. Revista Latinoamericana de Estudios de Familia, 12(1), 165-185. DOI: $10.17151 /$ rlef.2020.12.1.10

Parke, R. (1986). El papel del padre. Ediciones Morata.

Quilodrán, J. (2001). Parejas conyugales en transformación. El Colegio de México. 
Rabell, C. (2009). Tramas familiares en el México contemporáneo. Una perspectiva sociodemográfica. UNAM - El Colegio de México.

Rojas, O. L. (2000). La paternidad y la vida familiar en la ciudad de México, un acercamiento cualitativo al papel desempeñado por los varones en los ámbitos reproductivo y doméstico (tesis de doctorado). El Colegio de México, A. C., Centro de Estudios Demográficos y de Desarrollo Urbano, México.

Rojas, O. L. (2006). Reflexiones en torno a las valoraciones masculinas sobre los hijos y la paternidad. En J. G. Figueroa, L. Jiménez y O. Tena (Eds.). Ser padres, esposos e hijos: Prácticas y valoraciones de varones mexicanos (pp. 95-119). El Colegio de México.

Rojas, O. L. (2007). Criar a los hijos y participar en las labores domésticas sin dejar de ser hombres: un estudio generacional en la ciudad de México. En A. Amuchástegui e I. Szasz, (Coords.). Sucede que me canso de ser hombre... Relatos y reflexiones sobre hombres y masculinidades en México (pp. 519-562). El Colegio de México.

Roopnarine, J. L. (2013). Fathers in Caribbean cultural communities. En D. Shwalb, B. Shwalb y M. E. Lamb (Eds.). Fathers in cultural context (pp. 203-227). Routledge.

Ruiz, R. (1997). La construcción de la paternidad y la maternidad en nuevos padres y madres (tesis). UNAM, FES-Iztacala.

Saldaña, L. y Salgado, C. J. (2018). Paternidades en el Concepción urbano. Prácticas de crianza, reedición del rol paterno e identidad masculina. En N. Fuller (Ed.). Es difícil ser hombre. Nuevas masculinidades latinoamericanas (pp. 168-195). Pontificia Universidad Católica del Perú, Fondo Editorial.

Salguero, M. A. (2002). Significado y vivencia de la paternidad en el proyecto de vida de los varones (tesis doctoral). Universidad Nacional Autónoma de México.

Salguero, M. A. (2006). Significado y vivencia de la paternidad en algunos varones de sectores socioeconómicos medios en la Ciudad de México. En J. G. Figueroa, L. Jiménez y O. Tena (Eds.). Ser padres, esposos e hijos: Prácticas y valoraciones de varones mexicanos (pp. 57-94). El Colegio de México.

Salguero, M. A. (2007). Preguntarse cómo ser padre, es también preguntarse cómo ser hombre: reflexiones sobre algunos varones. En A. Amuchástegui e I. Szasz (Coords.). Sucede que me canso de ser hombre... Relatos y reflexiones sobre hombres y masculinidades en México (pp. 563-599). El Colegio de México.

Salguero, M. A. (2008). Ni todo el poder ni todo el dominio: identidad en los varones, un proceso de negociación entre la vida laboral y la familiar. En J. C. Ramírez y G. Uribe (Coords.) MASCULINIDADES. El juego de género de los hombres en el que participan las mujeres (pp. 247-268). Plaza y Valdés.

Salguero, M. A. (2013). Masculinidad como configuración dinámica de identidades. En J. C. Ramírez y J. C. Cervantes (Coords.). Los hombres en México, veredas recorridas y por andar (pp. 37-52). CUCEA, AMEGH.

Salguero, M. A. y Pérez, G. (2008). La paternidad en los varones: Una búsqueda de identidad en un terreno desconocido. Algunos dilemas, conflictos y tensiones. Revista Internacional de Estudios sobre Masculinidades, III(4), 1-18. 
Reflexiones sobre los cambios en las relaciones de género en las familias...

Salguero, M. A. y Pérez, G. (2011a). Dilemas y conflictos en el ejercicio de la maternidad y la paternidad. UNAM, FES-Iztacala.

Salguero, M. A. y Pérez, G. (2011b). La paternidad en el cruce de perspectivas: El discurso reflexivo de padres y madres. Géneros, 18(9), 35-56.

Salguero, M. A. y Yoseff, J. (2020). Presencias y ausencias paternas desde una aproximación sociocultural de género. UNAM, FES-Iztacala.

Salinas, L. (2002). Derecho, género e infancia. Mujeres, niños, niñas y adolescentes en los Códigos Penales de América Latina y el Caribe Hispano. UAM-Universidad Nacional de Colombia-UNIFEM.

Salles, V. y Tuirán, R. (1998). Cambios demográficos y socioculturales: familias contemporáneas en México. En B. Schmukler (Coord.). Familias y relaciones de género en transformación (pp. 83-126). EDAMEX/Population Council.

Torres, L. E. (2002). Ejercicio de la paternidad en la crianza de hijos e hijas (tesis de doctorado). Universidad Nacional Autónoma de México.

UNICEF. (2007). Presentación de la Convención sobre los Derechos del Niño. http://www.unicef.org/ $\mathrm{spanish} / \mathrm{crc} /$

Vassallo, J. (2011). ¿Leyes patriarcales para parejas modernas? La regulación legal de las parejas conyugales en Latinoamérica. En J. Quilodrán (Coord.). Parejas conyugales en transformación. El Colegio de México. 